\title{
Influenza-associated Aspergillosis in Critically III Patients
}

Citation for published version (APA):

van de Veerdonk, F. L., Kolwijck, E., Lestrade, P. P. A., Hodiamont, C. J., Rijnders, B. J. A., van Paassen, J., Haas, P-J., dos Santos, C. O., Kampinga, G. A., Bergmans, D. C. J. J., van Dijk, K., de Haan, A. F. J., van Dissel, J., van der Hoeven, H. G., Verweij, P. E., \& Dutch-Belgian Mycoses Study Grp (2017). Influenza-associated Aspergillosis in Critically III Patients. American Journal of Respiratory and Critical Care Medicine, 196(4), 524-527. https://doi.org/10.1164/rccm.201612-2540LE

Document status and date:

Published: 15/08/2017

DOI:

10.1164/rccm.201612-2540LE

Document Version:

Publisher's PDF, also known as Version of record

Document license:

Taverne

Please check the document version of this publication:

- A submitted manuscript is the version of the article upon submission and before peer-review. There can be important differences between the submitted version and the official published version of record.

People interested in the research are advised to contact the author for the final version of the publication, or visit the DOI to the publisher's website.

- The final author version and the galley proof are versions of the publication after peer review.

- The final published version features the final layout of the paper including the volume, issue and page numbers.

Link to publication

\footnotetext{
General rights rights.

- You may freely distribute the URL identifying the publication in the public portal. please follow below link for the End User Agreement:

www.umlib.nl/taverne-license

Take down policy

If you believe that this document breaches copyright please contact us at:

repository@maastrichtuniversity.nl

providing details and we will investigate your claim.
}

Copyright and moral rights for the publications made accessible in the public portal are retained by the authors and/or other copyright owners and it is a condition of accessing publications that users recognise and abide by the legal requirements associated with these

- Users may download and print one copy of any publication from the public portal for the purpose of private study or research.

- You may not further distribute the material or use it for any profit-making activity or commercial gain

If the publication is distributed under the terms of Article $25 \mathrm{fa}$ of the Dutch Copyright Act, indicated by the "Taverne" license above, 


\section{Influenza-associated Aspergillosis in Critically III Patients}

\section{To the Editor:}

Invasive aspergillosis is a well-known complication in immunocompromised patients but may also develop in patients with influenza pneumonia. The largest reported series included nine cases of invasive aspergillosis among 40 critically ill patients with influenza A H1N1 infection (23\%) over a period of 3 years in two centers (1). Influenza-associated aspergillosis (IAA) may develop in immunocompromised patients $(1,2)$, but it has also been reported in apparently immunocompetent patients and was associated with the use of corticosteroids $(1,3,4)$. Review of all 68 cases with IAA reported during the last 60 years indicated an overall mortality rate of $47 \%$ (5).

We conducted a multicenter retrospective observational study involving all eight academic tertiary care intensive care units (ICUs) in the Netherlands from December 2015 to April 2016, aimed at describing the diagnosis, treatment, and outcome of IAA in adults. All data were processed anonymously, and the ethics committee waived informed consent.

Influenza cases were identified both by reviewing all patients with a positive influenza polymerase chain reaction in the registry of the local microbiology department and matching these with ICU admission, and via using national ICU registrations of viral pneumonia and oseltamivir treatment to identify patients diagnosed with influenza or treated for influenza at a referring hospital. The IAA case definition included confirmed influenza diagnosis based on a positive result from a reverse transcriptase polymerase chain reaction test for influenza $A$ and $B$ from nasopharyngeal swab, sputum, or bronchoalveolar lavage (BAL) fluid. Furthermore, new infiltrates on the chest X-ray or computed tomography scan had to be present, as well as clinical symptoms including refractory fever or worsening of respiratory insufficiency despite more than 3 days of antibiotic therapy, dyspnea, hemoptysis, and/or pleural friction rub. Mycological evidence included histopathology or direct microscopic evidence of dichotomous branching hyphae with positive culture for Aspergillus from tissue. In addition, a galactomannan optical index in BAL of more than 1 or in serum of more than 0.5 within 3 weeks of influenza diagnosis was considered sufficient evidence for the diagnosis of IAA (4). After 3 weeks, other factors, such as corticosteroid use, may contribute substantially to the risk of developing invasive aspergillosis (4). Patients were classified if host, clinical, and mycological factors were present. A web-based case record form was used to collect microbiological and clinical data. For each center, the number of influenza cases admitted to the ICU within the 4-month period was collected. Data were analyzed with SAS 9.2 (SAS Institute Inc., Cary, NC).

Between December 1, 2015, and March 31, 2016, 144 influenza cases were admitted to the ICU of the eight centers, of which

Author Contributions: Study design: F.L.v.d.V., E.K., J.v.D., and P.E.V.; information technology and database: P.P.A.L.; data collection: F.L.v.d.V., E.K., C.J.H., B.J.A.R., J.v.P., P.-J.H., C.O.d.S., G.A.K., D.C.J.J.B., K.v.D., H.G.v.d.H., and P.E.V.; data analysis: F.L.V.d.V., E.K., P.P.A.L., and P.E.V.; statistical analysis: A.F.J.d.H.; writing of first draft: F.L.v.d.V., E.K., and P.E.V.; and revision of manuscript: all authors.

Originally Published in Press as DOI: 10.1164/rccm.201612-2540LE on April 7, 2017
23 (16\%) matched our IAA case definition (Table 1). Influenza A was found in 21 patients (91\%), and all patients received oseltamivir or zanamivir therapy. Our patient cohort included 14 males and 9 females, and the median age was 62 years (range, 34-80 years; Table 1). A preexisting underlying condition was present in 16 patients (70\%), which could be classified as high risk (2 patients), intermediate risk ( 2 patients), low risk (6 patients), and no risk for invasive fungal disease (4 patients) (6). None were neutropenic. In seven patients $(30 \%)$, no underlying disease was present at the time of acquiring influenza (Table 1 ).

Galactomannan was detected in BAL fluid of 17 of 18 patients (94\%), whereas BAL culture was positive in 14 patients $(78 \%$; Table 1). Serum galactomannan was determined in 14 patients, of whom 10 were positive (71\%). In 14 patients, in vitro susceptibility testing was performed, and azole resistance was found in 4 (29\%), including 3 patients who harbored both azole-susceptible and azoleresistant isolates (7). Fourteen (61\%) of 23 patients with IAA died, all during ICU admission. Five (71\%) of the 7 previously healthy patients died compared with $9(56 \%)$ of 16 patients with preexisting underlying conditions. In three patients (Table 1), autopsy showed evidence of necrosis and erosion of the epithelium of the trachea and bronchi, with invasive hyphal growth. The median time to initiation of antifungal therapy from the day of the influenza diagnosis was 9 days compared with 2 days in nonsurvivors and survivors, respectively (Mann-Whitney $P=0.06$; 95\% confidence interval for the difference, -0.2 to 13 ; Figure 1 ).

We observed IAA in critically ill patients with influenza and identified 11 patients who were previously healthy (seven) or had no known risk for invasive aspergillosis (four). The mortality rate of IAA was high; it was higher than the previously reported $47 \%$ mortality rate (5). The mortality rate among patients without risk factors was not lower compared with those with low, intermediate, or high risk for invasive fungal disease. Delayed diagnosis of IAA in the ICU and subsequent delayed antifungal therapy might have contributed to this high mortality. The clinical presentation of IAA differed substantially from presentations seen in patients with classic risk factors. The observation of two patients with Aspergillus tracheobronchitis underscores the need to further characterize clinical and radiological features of IAA (8). Furthermore, a high triazole resistance frequency was observed, which appears to be higher in the Netherlands than in other countries and further compromises successful patient management (9).

It is important to understand the pathogenesis of IAA from the perspective of virus, fungus, and host. Strikingly, in line with our observation, almost all cases to date have been associated with the pandemic influenza A H1N1 infection. Although it has been shown that early treatment with antiviral drugs in influenza reduces mortality, especially in adults (10), we observed a very high mortality of $61 \%$, despite antiviral therapy. Whether influenza A H1N1 has unique properties that predispose to IAA remains to be investigated.

In a previous study, corticosteroid treatment was suggested to be the main risk factor for developing IAA in the ICU (1). Although 18 of 23 patients received steroids, our cohort also included 5 patients who did not receive corticosteroids, and 2 of them had no underlying condition. This suggests that corticosteroids might not be the only predisposing factor contributing to IAA.

Our study indicates that increased awareness of IAA as an early complication of influenza, prompt diagnoses, and initiation 


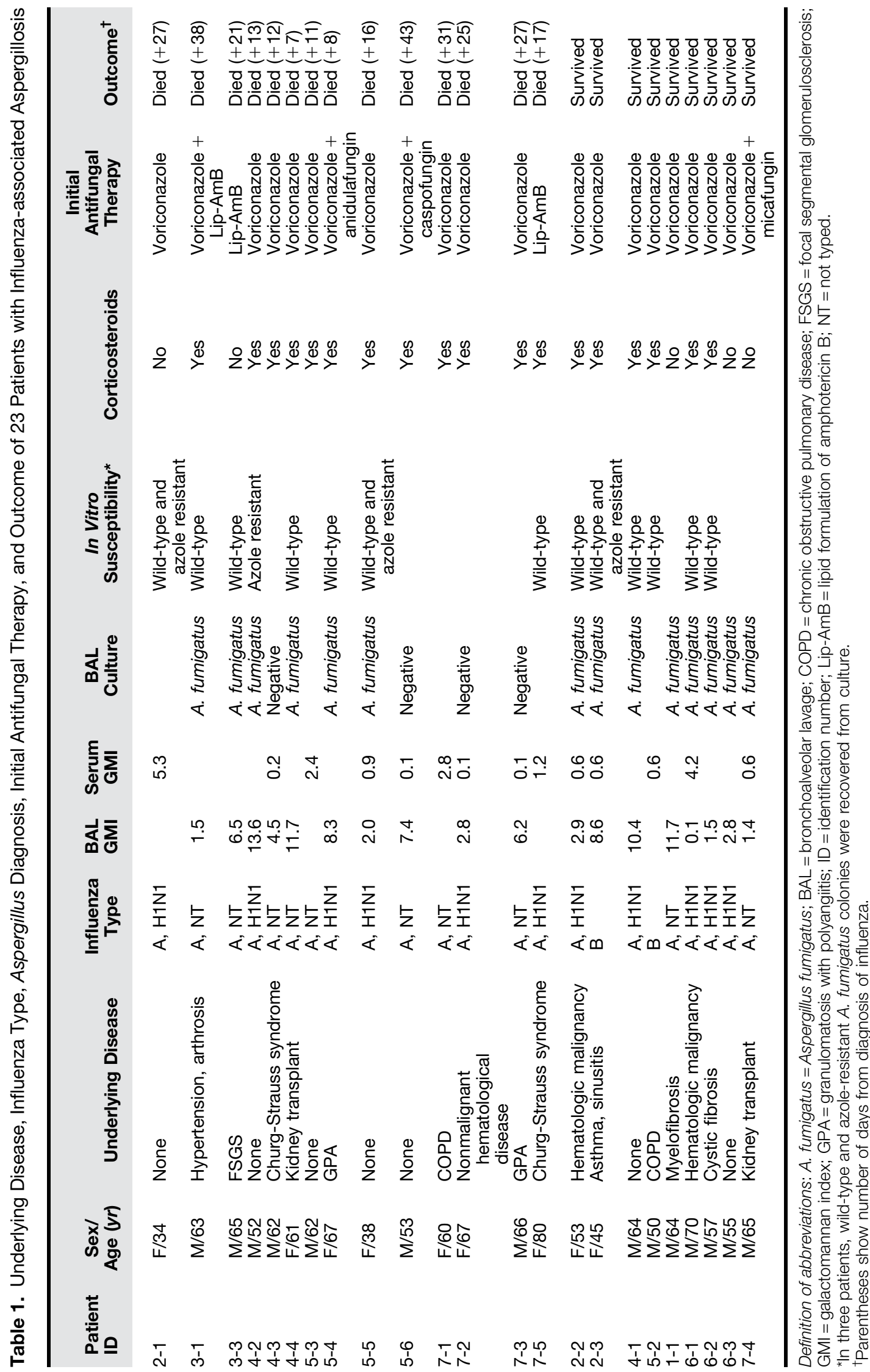


Onset influenza symptoms

ICU admission

Start mechanical ventilation

First infiltrate chest X-ray

First indication IPA

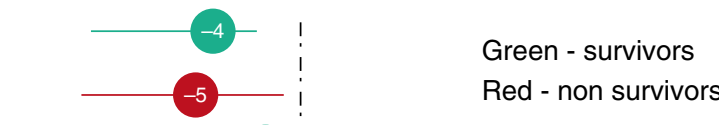

Red - non survivors

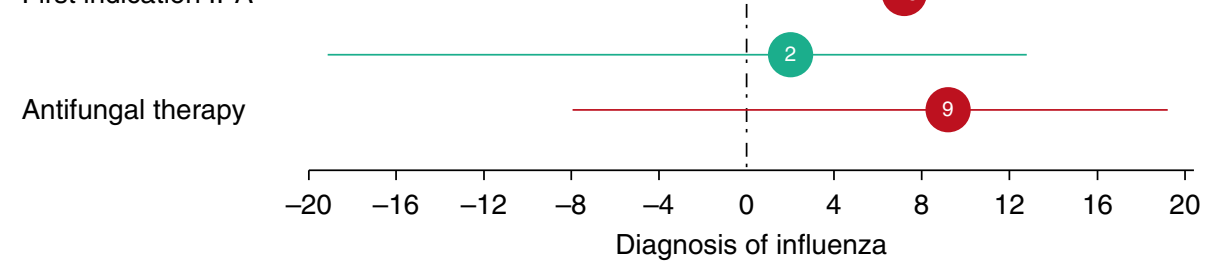

Figure 1. The median and range time to event from influenza diagnosis for survivors and nonsurvivors. The $x$-axis shows the number of days from diagnosis of influenza, with confirmed diagnosis at Day 0. ICU = intensive care unit; IPA = invasive pulmonary aspergillosis.

of appropriate antifungal therapy might prove to be important to decrease mortality of influenza in coming seasons.

\section{Author disclosures are available with the text of this letter at www.atsjournals.org.}

Frank L. van de Veerdonk, Ph.D., M.D.

Eva Kolwijck, Ph.D., M.D.

Pieter P. A. Lestrade, M.D.

Radboud University Medical Centre

Nijmegen, the Netherlands

Caspar J. Hodiamont, Ph.D., M.D.

Academic Medical Centre

Amsterdam, the Netherlands

Bart J. A. Rijnders, Ph.D., M.D.

Erasmus Medical Centre

Rotterdam, the Netherlands

Judith van Paassen, M.D.

Leiden University Medical Centre

Leiden, the Netherlands

Pieter-Jan Haas, Ph.D., M.D.

University Medical Centre

Utrecht, the Netherlands

Claudy Oliveira dos Santos, M.D.

Greetje A. Kampinga, Ph.D., M.D.

University Medical Centre Groningen

Groningen, the Netherlands

Dennis C. J. J. Bergmans, Ph.D., M.D.

Maastricht University Medical Centre

Maastricht, the Netherlands

Karin van Dijk, Ph.D., M.D.

VU University Medical Centre

Amsterdam, the Netherlands
Anton F. J. de Haan, M.Sc.

Radboud University Medical Centre

Nijmegen, the Netherlands

Jaap van Dissel, Ph.D., M.D.

National Institute of Public Health and the Environment

Bilthoven, the Netherlands

Hans G. van der Hoeven, Ph.D., M.D.

Paul E. Verweij, Ph.D., M.D.

Radboud University Medical Centre

Nijmegen, the Netherlands

Dutch-Belgian Mycoses Study Group*

${ }^{*}$ The Dutch-Belgian Mucosis Study Group includes the following participants: Janette C. Rahamat-Langendoen, Bart-Jan Kullberg, Mihai G. Netea, Roger J. Brüggeman, Astrid W. Hoedemaekers, and Willem J. G. Melchers (Radboud University Medical Centre, Nijmegen); Wieke Freudenburg, Nienke Roescher, W. Joost Wiersinga, and Charlotte H. S. B. van den Berg (Academic Medical Centre, Amsterdam); Alieke G. Vonk, Carla van Tienen, and Ben van der Hoven (Erasmus Medical Centre, Rotterdam); Martha T. van der Beek (Leiden University Medical Centre, Leiden); Lennie P.G. Derde (University Medical Centre Utrecht, Utrecht); Coretta van Leer and Heleen Aardema (University Medical Centre Groningen, Groningen); Astrid Oude Lashof (Maastricht University Medical Centre, Maastricht); and C. Wim Ang (VU University Medical Centre, Amsterdam).

\section{References}

1. Wauters J, Baar I, Meersseman P, Meersseman W, Dams K, De Paep R, Lagrou K, Wilmer A, Jorens P, Hermans G. Invasive pulmonary aspergillosis is a frequent complication of critically ill H1N1 patients: a retrospective study. Intensive Care Med 2012;38:1761-1768.

2. Garcia-Vidal C, Barba P, Arnan M, Moreno A, Ruiz-Camps I, Gudiol C, Ayats J, Ortí G, Carratalà J. Invasive aspergillosis complicating pandemic influenza $A(\mathrm{H} 1 \mathrm{~N} 1)$ infection in severely immunocompromised patients. Clin Infect Dis 2011;53:e16-e19.

3. Lat A, Bhadelia N, Miko B, Furuya EY, Thompson GR III. Invasive aspergillosis after pandemic (H1N1) 2009. Emerg Infect Dis 2010;16:971-973.

4. De Pauw B, Walsh TJ, Donnelly JP, Stevens DA, Edwards JE, Calandra T, Pappas PG, Maertens J, Lortholary O, Kauffman CA, et al.; 
European Organization for Research and Treatment of Cancer/Invasive Fungal Infections Cooperative Group; National Institute of Allergy and Infectious Diseases Mycoses Study Group (EORTC/MSG) Consensus Group. Revised definitions of invasive fungal disease from the European Organization for Research and Treatment of Cancer/Invasive Fungal Infections Cooperative Group and the National Institute of Allergy and Infectious Diseases Mycoses Study Group (EORTC/MSG) Consensus Group. Clin Infect Dis 2008;46:1813-1821.

5. Alshabani K, Haq A, Miyakawa R, Palla M, Soubani AO. Invasive pulmonary aspergillosis in patients with influenza infection: report of two cases and systematic review of the literature. Expert Rev Respir Med 2015;9:89-96.

6. Pagano L, Akova M, Dimopoulos G, Herbrecht R, Drgona L, Blijlevens N. Risk assessment and prognostic factors for mould-related diseases in immunocompromised patients. J Antimicrob Chemother 2011;66: i5-i14.

7. Kolwijck E, van der Hoeven $H$, de Sévaux RG, ten Oever J, Rijstenberg LL, van der Lee HA, Zoll J, Melchers WJ, Verweij PE. Voriconazole-susceptible and voriconazole-resistant Aspergillus fumigatus coinfection. Am J Respir Crit Care Med 2016;193:927-929.

8. Lee JY, Joo EJ, Yeom JS, Song JU, Yim SH, Shin DS, Yu JH, Ju DY, Yim JW, Song YS, et al. Aspergillus tracheobronchitis and influenza A coinfection in a patient with AIDS and neutropenia. Infect Chemother 2014;46:209-215.

9. van Paassen J, Russcher A, in 't Veld-van Wingerden AW, Verweij PE, Kuijper EJ. Emerging aspergillosis by azole-resistant Aspergillus fumigatus at an intensive care unit in the Netherlands, 2010 to 2013. Euro Surveill 2016;21(30):ii=30300.

10. Muthuri SG, Venkatesan S, Myles PR, Leonardi-Bee J, Al Khuwaitir TS, Al Mamun A, Anovadiya AP, Azziz-Baumgartner E, Báez C, Bassetti M, et al.; PRIDE Consortium Investigators. Effectiveness of neuraminidase inhibitors in reducing mortality in patients admitted to hospital with influenza A H1N1pdm09 virus infection: a metaanalysis of individual participant data. Lancet Respir Med 2014;2: 395-404.

Copyright (C) 2017 by the American Thoracic Society

\section{Vascular Stiffness and Mechanotransduction: Back in the Limelight}

\section{To the Editor:}

Decades of extensive research in the field of pulmonary hypertension $(\mathrm{PH})$ have led to the discovery of several pathogenic drivers and, thus, targeting possibilities. Despite that, there remains a lack of effective therapeutic options with major vasodilation therapies that have a limited influence on vascular remodeling (1). Vascular remodeling, characterized by medial wall thickening, plexiform lesions, and intimal hyperplasia, is an outcome of excessive proliferation, migration, and survival of pulmonary artery smooth muscle cells (PASMCs), endothelial cells, and fibroblasts (2). This therapeutic deficit demonstrates a need for intensive investigation of the detailed mechanisms underlying vasodilation and vascular remodeling and, preferably, determining a link between them to target them together. Although vascular stiffening associated with aberrant collagen and elastin deposition in the extracellular matrix (ECM) at end-stage $\mathrm{PH}$ has been long recognized (3), emerging evidence also supports the idea that stiffening can precede the development of $\mathrm{PH}$ and promotes pulmonary vascular remodeling $(4,5)$. Vascular stiffness in the proximal and distal pulmonary arterial tree occurs in various forms of $\mathrm{PH}(3,6)$, and stiffness is an index of disease progression (7). Furthermore, recent studies demonstrate that pulmonary vascular (PV) stiffness has significant prognostic value in PH. PV stiffness correlates with mortality in patients with $\mathrm{PH}$, and moreover, measurements of PV stiffness are considered to be more accurate in assessing right ventricular afterload and may even be superior to PV resistance in predicting mortality $(8,9)$. These observations raise the possibility that PV stiffness is a critical factor that must be treated to improve outcomes for patients with $\mathrm{PH}$.

However, the exact role of vascular stiffening in the development and progression of $\mathrm{PH}$ has yet to be defined. In particular, the field has lacked a clear understanding of the spatiotemporal development of PV stiffness and what distinct responses to proximal versus distal PV stiffening contribute to $\mathrm{PH}$ pathogenesis and progression. In addition, although it is becoming increasingly clear that measurement of changes in PV stiffness/arterial flow pulse waves are likely to be incorporated into medical practice for diagnosis or prognosis of $\mathrm{PH}$, many remain skeptical that vascular stiffness is a desirable treatment target. A major contributor to this skepticism is the lack of studies delineating a causal relationship between artery stiffness and $\mathrm{PH}$ progression.

An essential question that further arises is what exactly leads to an increase in distal vascular stiffness in response to pathological stimuli. In parallel, we do not know how early changes in the local mechanical environment contribute to progressive vascular remodeling and promote the development of $\mathrm{PH}$. What are the mechanosensitive pathways/factors that are activated, and how can they regulate cellular proliferation, survival, metabolism, and the ECM, particularly during the development and progression of $\mathrm{PH}$ ?

Three recent and independent studies shed light on these important issues. Together, Liu and colleagues (5) and Bertero and colleagues (10) suggest that vascular stiffness-induced mechanical stress is sufficient to activate cellular pathways in vascular cells, leading to enhanced proliferation, migration, and matrix deposition. These changes can, in turn, further perpetuate vascular stiffness, giving rise to a self-sustainable loop amplifying vascular remodeling in $\mathrm{PH}$. Ruffenach and colleagues (11) provide strong support in favor of microRNA(miR)-204/Runt-related transcription factor 2 (RUNX2)/hypoxia-inducible factor- $1 \alpha$ axis as a driver of stiffness via promoting vascular calcification in distal vasculature (Figure 1).

Human $\mathrm{PH}$ patients and animal models for $\mathrm{PH}$, such as hypoxic calves, rats, and mice, are all characterized by increased stiffness or reduced compliance of pulmonary arteries (PAs) and/or increased PA impedance $(6,12,13)$. Considerable work has been invested in understanding large vessel stiffening at the macroscopic level; however, little is known about distal wall stiffening. Liu and colleagues (5), taking the lead in this direction, demonstrated that PA stiffening arises in the distal vasculature, followed by stiffening of more proximal vessels in two rat models of $\mathrm{PH}$ : monocrotaline (MCT) and Su5416/hypoxia. This stiffening took place early in the course of experimental $\mathrm{PH}$, preceding alterations in hemodynamics or right ventricular dysfunction. This strongly suggested a causative role of vascular stiffening in the pathogenesis of $\mathrm{PH}$. These findings were supported by a significant increase in small vessel stiffness observed in patients with idiopathic pulmonary arterial hypertension. Further cementing this role, the authors showed that matrix stiffening directly activated the proliferation of PASMCs and pulmonary artery endothelial cells and triggered PASMCs to produce ECM and exaggerated traction forces. On the basis of their 